\title{
Estructura colonial y rebeliones andinas
}

\section{Heradio Bonilla}

Desde el momento mismo de la conquista española del área andina la población indígena fue protagonista de diferentes movilizaciones sociales en las que se expresaron, de una parte, el rechazo a la dominación imperial, de otra, la réplica a los abusos de la administración colonial o, lisa y llanamente, la intención de quebrar las bases del pacto colonial. Para el centro y sur Andinos - es decir los espacios correspondientes a las actuales Repúblicas del Perú y de Solivia - si bien no existe todavía un conocimiento adecuado de la estructura de estos movimientos, por lo menos se dispone de una cronología de los mismos. Durante todo el siglo XVI, por ejemplo, movimientos como los del Taki Onoy (1565) o los de Vilcabamva (hasta su destrucción en 1572), tradujeron la resistencia de la población india a su subordinación colonial, al mismo tiempo que buscaron la reconstrucción, desde sus escombros, de las sociedades andinas destruidas por la invasión española. En el XVII, probablemente como consecuencia de un sensible declive de la población india y del éxito re* lativo del acondicionamiento colonial imple- mentado por Toledo, se estableció en el seno de la población dominada una suerte de pax andina, cuya expresión fue justamente la ausencia de significativas rebeliones indias. Es en el XVIII cuando toda esta región andina es virtualmente sacudida por violentas movilizaciones indias, las que expresaron tanto un mayor deterioro en la condición material de la población nativa, como un incremento significativo de la explotación colonial impuesto por la administración borbónica. Juan Santos Atahualpa, en la ceja de selva entre 1742 y 1761, Francisco Inca en Huarochiri en $1750, y$, sobre todo, las rebeliones lideradas por Tomas y Tupac Catari, de una parte, y Tupac Amaru, de otra, en el sur andino entre 1780 y 1783, representaron justamente las cimas en este despertar de la protesta india.

En el norte andino, en la actual República del Ecuador, se sabía de la existencia de movilizaciones indígenas en el XVI (Quito, Lita, Quilca y Caguasqui), en el XVII (sobre todo en las zonas de frontera de selva de la colonización), pero no se conocía ni la estructura ni el sentido de estas rebeliones en el siglo XVIII. Esta laguna empie- 
za a ser colmada gracias a las Sublevaciones indígenas en la Audiencia de Quito (Bonn, 1976, III-454 pp.) del antropólogo ecuatoriano Segundo Moreno Yáñez, trabajo inicialmente presentado como tesis doctoral en la Facultad de Filosofía y Letras de la Universidad de Bonn, Alemania. Se abre así la posibilidad no sólo de comprender la naturaleza intrínseca de estas rebeliones, sino de establecer (a través de una comparación con las rebeliones ocurridas en las otras regiones de los Andes) las correlaciones que existieron entre estructura de una sociedad y estructura de una rebelión.

Bien conocido es el hecho de la incorporación tardía de los pueblos y territorios nor-andinos al seno del Tahuantinsuyo: 50 a 80 años antes de la invasión hispánica. Esto explica la vulnerabilidad de la dominación Inca en esta región y la adhesión de sus grupos a las huestes de Pizarro. El descubrimiento de Potosí y Huancavelica, más tarde, convirtieron al sur andino en el nervio de la colonización americana, vertebrando en torno suyo prácticamente a la totalidad del espacio del virreinato peruano. La mediocridad de los yacimientos de Zaruma y las imposiciones de la política colonial, hicieron de la región quiteña un área fundamentalmente centrada en la producción textil y agropecuaria para el abastecimiento de los mercados centro y sur andinos. Hasta la emergencia tardía de las plantaciones guayaquileñas, el obraje y el tradicional latifundio andino simbolizaron la vocación de su economía. La apropiación de la fuerza de trabajo de la población sometida, vía la mita colonial, fue realizada por lo mismo al interior de estas unidades de explotación. La evasión de los indios a estos mecanismos compulsivos de trabajo, traducido en la emergencia de una importante población "forastera", asociada a la destrucción física de la población indígena al interior de los obrajes, determinaron la cancelación de la mita obrajera en 1704 y, un siglo más tarde, la supresión de la mita agraria por las Cortes de Cádiz. Desaparecía así uno de los fulminantes que habían pro- vocado en el sur peruano las rebeliones indias, Pero una economía organizada sobre estas bases era por lo mismo extremadamente sensible a cambios que debilitaran su nexo con ios mercados de las regiones más dinámicas del virreinato peruano o que alteraran la estructura y el tipo de su producción. En el caso de Quito, como en el Alto Perú, tales cambios estuvieron estrechamente asociados a la implementación de las reformas borbónicas ${ }^{1}$. Ellas crearon la coyuntura de la rebelión, en una estructura caracterizada por una secular opresión de la población india. Estas reformas estuvieron orientadas a la reconquista del espacio americano para la Corona metropolitana, es decir a quebrar un conjunto de privilegios internos que la impidieron obtener el provecho máximo de la explotación de sus colonias ultramarinas. El restablecimiento de esta racionalidad en la explotación colonial fue pensado como uno de los mecanismos para cerrar la brecha existente entre el nivel del crecimiento económico de la península ibérica y el de las regiones más pujantes del continente europeo. Una mayor liberalización del comercio ultramarino, el incremento de la recaudación fiscal por la imposición de nuevos tributos y por una mayor eficiencia en su recaudación, así como la reasignación del trabajo de la población sometida (sobfe todo de aquella que a través de diversos mecanismos había logrado escapar a la obligación de la mita) a estos nuevos fines productivos fueron, en el contexto de esta discusión, los elementos de la política de los Borbones. Veamos sus efectos en la economía y sociedad quiteñas del siglo XVIII.

Para este período la población de la Audiencia de Quito fue calculada en medio millón de habitantes, de los cuales la mitad eran indios. Pero la mayoría de esta población indígena, a diferencia de la región central del virreinato peruano y a semejanza del Alto Perú, era "forastera" y no llactaya, es decir desarraigada de lo que habían sido sus centros coloniales de asentamiento: las reducciones toledanas. Desafortunadamente se 
desconocen los. mecanismos concretos que indujeron esta portentosa movilidad andina, pero es posible suponer que estuvo asociada a la reacción campesina en contra de la mita y de la tributación. Dos ejemplos que testimonian de la amplitud de este problema. Moreno Yúñez señala que en Riobamba, Cajabamba y Calpi eí $65 \%$ de su población era "forastera" y sólo el 35\% originaria (pg. 47), mientras que en Caldas, en el corregimiento de Otavalo, se contaban entre 12 a 14 mil "forasteros" frente al sólo 2 mil indios originarios (pg. 393). De aquí entonces la profunda sensibilidad y hostilidad de esta población a toda tentativa de ser recensada ("numerada" en el lenguaje de la burocracia colonial) por los funcionarios de la Audiencia. Tales recuentos eran asociados, en la conciencia de la población sometida, a la imposición de nuevos gravámenes fiscales o a su reencuadramienío colonial (vía la coacción tributaria) que su condición de "forastera" le había permitido relativamente evadir.

La liberalización del comercio y de la política mercantilista, por otra parte, al abrir puertos y mercados a la producción textil europea llevó al colapso de las artesanías nativas, cuya obsolescencia tecnológica las inhabilitaba para competir con éxito frente a la producción foránea. La región quiteña, como poco más tarde el conjunto del Alto Perú, dada la naturaleza de su estructura productiva fue particularmente permeable a los efectos disruptivos producidos por la invasión de los textiles europeos. Las consecuencias son fáciles de prever: el éxodo masivo de los trabajadores indios que previamente estuvieron incorporados en la producción textil y. con la cancelación de estas fuentes de trabajo, una significativa erosión de la condición cíe la vida material indígena. Así, poco a poco, fueron constituyéndose las condiciones objetivas de la rebelión.

La aplicación de las reformas fiscales de los Borbones, finalmente, produjeron un incremento sensible de las rentas recaudadas. Moreno Yáñez señala a este respecto que el monto de la tributación indígena as- cendía a 1764,065 pesos entre 1779-1787, es decir un $30 \%$ sobre el valor recaudado en el quinquenio precedente, cuando esta recaudación era realizada por "asentistas" particulares (pg. 374). Pero lo que era bueno para el gobierno no necesariamente era bueno para los colonizados. En efecto, el incremento de las rentas fiscales de la Audiencia de Quito sólo pudo haber sido logrado a través de una mayor extorsión de la ya pauperizada población indígena.

Es el análisis de la defensa de la población india de la Audiencia de Quito en contra de todo intento de incrementar la explotación fiscal que constituye el aporte esencial del libro de Segundo Moreno. Cerca de 340 páginas, de un total de 433, están en efecto destinadas a una descripción rigurosa de los móviles, de la mecánica y del epílogo de 10 rebeliones que cortaron la historia social de Quito entre 1730 y 1810 . No es un mérito menor el haber rescatado para la historia documentos hasta hoy enterrados en el Archivo General de Indias de Sevilla, en el Archivo Histórico Nacional de Madrid y en el Archivo Nacional de Historia de Quito y cuya lectura contemporánea supera largamente la alucinación despertada por cualquier novela de ficción. Grande fue sin duda la explotación impuesta sobre los humildes, como grandiosos los combates que libraron en defensa de su humanidad y en defensa de su cultura, que es también componente de la nuestra. Los testimonios recopilados por Moreno, provienen de fuentes privilegiadas como son los juicios establecidos contra los rebeldes y constituyen, por si fuera necesario, una suerte de epitafio moral del Occidente. Recíprocamente, en su desesperanza y en sus mismas derrotas, estas rebeliones del ayer, como las de hoy, encierran la irrenunciable búsqueda de una promesa mejor. Es por esto que sin la menor duda la obra de Segundo Moreno pertenece a los intentos más serios para devolver a los oprimidos la historia que les fue arrebatada.

Para el estudio de las rebeliones indias en el Quito del XVIII Moreno toma diez 
casos: Pomallacta (1730), Alausí (1760), Ríobamba (1764), San Miguel de Molleambato (1766), Obraje de San Ildefonso (1768), San Felipe (1771), Otavalo (1777), Pueblo de Guano (1778), Ambato (1780), Guamote y Columbe (1803). Concomitantemente con esta cronología es importante constatar que hasta la rebelión de Otavalo de 1777, la coyuntura revolucionaria correspondió a una coyuntura espacial esencialmente simétrica constituida por una expansión de las movilizaciones indígenas, como mancha de aceite, de sur a norte. Es sólo después de la rebelión de Ambato (1780) que el sur de la Audiencia de Quito parece convertirse en una zona endémicamente rebelde. De las 10 rebeliones analizadas por el autor, por otra parte, las ocho últimas obedecieron a un móvil estrictamente anti-fiscal. Es decir que detrás de diferentes pretextos la razón esencial radicó en una cerrada oposición a todo intento de alterar o de imponer una nueva tributación. La "numeración" y las "aduanas" fueron así las banderas en contra de las cuales se rebeló la población india. Como por definición ellas implicaron el establecimiento de nuevas cargas impositivas sobre los bienes de consumo, o la adscripción de una parte de esta población a los trabajos compulsivos, no es extraño encontrar en los rangos de los rebeldes a las mujeres indias. Como administradoras de la economía familiar $\mathrm{y}$, sobre todo, como madres, la población femenina era en efecto la más sensible a este tipo de extorsión fiscal; de ahí la conmovedora violencia de sus actos. La rebelión de Pomallacta de 1730, en cambio, estuvo fundamentalmente orientada a la defensa de las tierras de la comunidad frente al avance del latifundio controlado por los blancos, mientras que la de Alausí, en 1760, tuvo como pretexto el deseo de los indios de que se respetara su tradicional derecho a encontrar asilo en el interior de la Iglesia.

Se mencionó anteriormente que los mayores detonantes de las rebeliones del Alto Perú fueron la mita y el llamado "reparto" de mercancías, es decir, la venta forzo- sa de mercancías superfluas a la población india. El movimiento de Tupac Amaru es el que mejor ilustra este tipo de móviles. En la región de Quito, en cambio, el crecimiento de la población forastera, así como la supresión temprana de la mita en favor de los obrajes retiraron la cancelación de la obligación compulsiva al trabajo como uno de los objetivos de la rebelión. Jorge Juan y Antonio de Ulloa en sus Noticias Secretas de América, por otra pane, señalan la inexistencia del reparto de mercancías en la Audiencia de Quito. Pese a que Moreno, apoyado en otros testimonios contemporáneos, reduce el alcance de la afirmación anterior, indicando más bien la existencia, pero limitada, del reparto de mercancías (pg. 378), es necesario sin embargo una explicación más convincente del por qué esta típica institución colonial tuvo nula o escasa significación en el área de Quito. En este sentido sería del más alto interés conocer cuál era el mecanismo de la ganancia de Corregidores y comerciantes locales. En la espera de estas respuestas basta constatar por ahora que la poca significación, como mecanismo de explotación, que revestía para los indios el reparto de mercancías explica por qué en ninguno de los diez casos propuestos figure la supresión de este reparto como logro a alcanzar.

Rebeliones básicamente anti-fiscales, en consecuencia. Por lo mismo estas rebeliones pudieron envolver tanto a indios como a mestizos, aunque obviamente por razones diferentes. A los primeros, en la medida que ellas traducían su protesta en contra del deterioro de su condición económica; a los mestizos, de otro lado, porque a través de estas movilizaciones rechazaron ser adscritos a la condición de indios, es decir susceptibles de ser tributarios. De los diez casos analizados, siete fueron de exclusiva participación india: Pomallacta, Riobamba, San Miguel de Molleambato, San Ildefonso, San Felipe, Otavalo y la de Columbe y Guamote. En ellas se expresaron $i$ como se indicó, la repulsión a una mayor extorsión fiscal, y 
también la defensa de las tierras de la comunidad (Pomallacta). En las otras tres, es decir las rebeliones de Alausí, del Pueblo de Guano y de Ambato, en cambio, se combinaron la participación de indios con la de mestizos y mulatos. La participación de los mestizos, sin embargo, demanda una mayor precisión.

En la medida que las reformas borbónicas afectaban la condición económica del conjunto de la población colonial, ellas creaban por lo mismo las bases mínimas para una articulación de los diferentes grupos, independientmente de la segmentación étnica. Este fue el caso de las movilizaciones en contra de nuevas alcabalas. Empero la ambigüedad de la condición colonial de los mestizos, asociado a que miembros de este grupo integraban el aparato de control y represión colonial y, last but not least, a que compartían con los blancos el mismo miedo y desprecio de la población nativa, hicieron que sus protestas en contra de la "numeración" encerraron en realidad su firme deseo de; no ser confundidos con los indios. De manera tangible esta fue la situación en Guano y en Ambato, mientras que la opción fundamental de los mestizos aparece en los levantamientos de San Miguel y San Ildefonso donde combatieron aliados a los españoles. Para la población indígena, de otro lado, la ambivalencia de los mestizos no pasó desapercibida: en Otavalo, en Columba y en Guamote se levantaron contra los españoles, a la vez que contra los mestizos.

Los indios forasteros del Alto Perú, para continuar con el análisis de la composición de estas rebeliones, constituyeron por su misma desubicación una población con una alta potencialidad de movilización, la más sensible, por ejemplo, a los llamados de criollos y mestizos. Su situación en Quito pareciera ser relativamente semejante. En efecto, la rebelión de Riobamba de 1764 muestra que la iniciativa de su organización y conducción correspondió por entero a los forasteros, en contra; de la numeración llevada a cabo por el oidor Félix de Llano que tendía a "reducir a los forasteros a la condición de llactayos, agregándolos a parcialidades y sujetándolos bajo el mando de caciques" (pg. 47).

Hablar de la participación "india", igualmente, requiere de una mayor precisión. Al interior de una condición étnica homogénea, la población india estuvo atravesada por divisiones ocupacionales, las cuales tuvieron también una incidencia en la rebelión. A este respecto es conveniente señalar que las rebeliones del Alto Perú y de las regiones centrales del espacio peruano básicamente fueron protagonizadas por los indios de las comunidades. Desafortunadamente el trabajo de Segundo Moreno no presta demasiada atención a este problema capital. Los indios forasteros, por ejemplo, ¿qué roles ocupacionales desempeñaban? En un solo caso, la rebelión de Otavalo en 1777, se dispone de la información suficiente como para intentar un corte ocupacional de la población sublevada. Recuérdese que el área de Otavalo estuvo caracterizada por la combinación de una producción textil $y$ agropecuaria $y$ que los levantamientos fueron básicamente de indios.

Los juicios entablados contra 103 rebeldes del área de Otavalo han permitido al autor describir la categoría ocupacional de cada uno de ellos (pg. 219). Si se procede a su reagrupamiento, el cuadro ocupacional que emerge es el siguiente:

labores agropecuarias

obrajes

autoridades étnicas

indios sueltos

sirvientes

albañiles

tejedor

barbero

sombrerero

mujeres

sin oficio 
El cuadro anterior permite establecer algunas constataciones. La primera y la más evidente es la alta participación femenina: poco menos de la mitad. La segunda se refiere a la participación igualmente importante de los indios involucrados en los trabajos de los obrajes y de las labores agropecuarias: un total de 39. Aquí, como el autor lo señala, existe una estrecha correlación entre el tipo de ocupación y los objetivos de la rebelión, es decir la destrucción de obrajes y haciendas que eran los centros donde se asignaba la fuerza de trabajo de los indios "numerados". Sin embargo la categoría de "labores agropecuarias" requiere todavía el indispensable deslinde entre la realizada por los indios de comunidad y los de hacienda. Es esta separación la que permitirá conocer la relación existente entre el grado de movilidad y la potencialidad de una protesta, entre conciencia y tipo de estructura productiva. Finalmente, los rebeldes indios considerados "sueltos" y ocupados! en diferentes "servicios" (sirvientes, albañiles, tejedores, barbe-ros, sombrereros) llegaban a 15. Dada su indiferenciación ocupacional es posible suponer que su adscripción al movimiento obedeció a estrictras razones étnicas. En todo caso, sería necesario ampliar las indagaciones en esta perspectiva en los otros levantamientos, con el objeto de llegar a un conocimiento más adecuado de la constelación de intereses que expresaron estos movimientos.

Toda rebelión, por espontánea que fuese, obedece a un liderazgo. En las rebeliones del sur peruano del siglo XVIII, nuevamente, este liderazgo fue ejercido básicamente por los caciques tradicionales, quienes, dada su posición de autoridad, podían obtener la pronta adhesión de sus subordinados. Esta actitud, en este contexto, contrasta radicalmente con la colaboración asumida con el conquistador en los primeros momentos de la colonización. La experiencia quiteña presenta también aquí una situación diferente. Moreno constata, en efecto, que sólo en los levantamientos de Pomallacta, Quisapincha y Atuntaqui existió una verdadera cohesión entre los caciques y los rebeldes (pg. 401). Todo pareciera indicar que el comportamiento típico de este grupo correspondió al asumido por los caciques de las parcialidades de Otavalo quienes, o bien fueron obligados por los rebeldes a sumarse al levantamiento (Cotacachi), o se escondieron ante el temor de ser asesinados por los indios. En el mismo Otavalo, sin embargo, la instructiva judicial acusa al cacique Luis Camuendo de haber suministrado pólvora a los rebeldes y de haber incitado a quemar el obraje de la Laguna del Rey (pg. 187).

Esta reticencia de los caciques, de otro lado, se transformó, en algunos casos, en una abierta alianza con las autoridades coloniales y en contra de sus propios subordinados indios. Es el caso de Leandro Sepia y Oro, cacique gobernador de Licán, quien ante el descontento de los indios por la "numeración" reunió a los caciques e indios de la región de Riobamba y los puso a disposición del Corregidor para ser utilizados como fuerzas auxiliares en defensa de la Villa (pg. 402).

La administración española, como parte de su política de acondicionamiento colonial de la población indígena, levantó un nuevo sistema de autoridad, paralelamente a la jerarquía tradicional, y que dependía directamente de la burocracia local. Ahora bien, en ausencia de los caciques que lideraran estas rebeliones es importante constatar, a la cabeza de estos movimientos, la presencia de alcaldes de pueblos, de alguaciles, de alcaldes de doctrina quienes disfrutaban también de una posición, aunque relativa, de prestigio y autoridad.

El problema, entonces, es cómo explicar el comportamiento de las autoridades tradicionales. ¿Fue debido a su mayor sujetamiento colonial, o a la naturaleza de las rebeliones quiteñas que al aspirar a la cancelación de la "numeración" y de las "aduanas" hacían de los caciques sus víctimas propiciatorias? Se sabe que la mediación de estas autoridades tradicionales era fundamental para obtener el enrolamiento de la fuer- 
za de trabajo indígena y la recaudación de los tribute $\AA$, función que precisamente los colocaba en la línea de mira de este tipo de levantamientos. Otra vez es indispensable aquí una investigación más profunda que examine ahora la naturaleza y la función de esta típica institución andina.

En lo concerniente a la dinámica de las rebeliones quiteñas cuatro son sus características fundamentales: espontaneidad, pequeñez, segmentación y precariedad. En el seno de una población sometida a una prolongada explotación colonial bastaba el anuncio de nuevas extorsiones para que los indios empezaran la organización de la resistencia. Pero estas movilizaciones escasamente comprometían a la población de una comunidad; eran radicalmente distintos, por lo mismo, de un levantamiento como el de Tupac Amaru que en 1781 movilizó a 100 mil indios en un arco que se extendía desde el Cuzco hasta Salta $^{2}$. De aquí también, pese a que estas rebeliones se inscribieron al interior de una impresionante coyuntura de agitación, su profundo aislamiento. Esta descoordinación de las rebeliones pudo traducir la estructura de colonización impuesta por los españoles o también deberse a la precariedad de la anexión de la región quiteña dentro del Tahuantinsuyo. $\mathrm{Su}$ aplastamiento, finalmente, fue rápidamente logrado por las milicias organizadas por la administración colonial, quienes mediante el empleo de las armas de fuego o de la aplicación de castigos ejemplares consiguieron disuadir a una población rebelde que combatía armada solamente de odio, de valor y de piedras.

Pero la sobriedad de esta descripción esconde dos problemas que es necesario ahora relievar. La transcripción realizada por Moreno del testimonio de los protagonistas de los bandos enfrentados pinta un alucinante cuadro de violencia ritualística, y cuyo desciframiento de su significado exacto exige una lectura totalmente distinta a la que está habituado el historiador tradicional. Aquí, probablemente, sea necesario reconstruir pieza a pieza la estructura mental de la pobla- ción andina recurriendo a las proposiciones de la Antropología y del Psicoanálisis. ¿Qué significan, por ejemplo, estos actos de canibalismo en contra de determinadas partes del cuerpo humano o aquellas danzas macabras y las no menos dantescas orgías de sangre? Ni la cólera de los oprimidos, ni su expresión, son actos gratuitos. Pero traducir su significado exige previamente descubrir la lógica interna que ordenó a la civilización de sus hombres. Pero es aquí, justamente, donde empieza nuestra ignorancia.

El segundo problema se refiere a la relación entre la Iglesia y la rebelión. Sumariamente, en el contexto del conjunto de la Hispanoamérica colonial la actitud de la Iglesia hacia la población indígena está simbolizada por Morelos e Hidalgo, de una paite, y por Moscoso y Peralta, el Obispo del Cuzco, de otra. Los primeros al conducir la rebelión de los indios mexicanos, el segundo al declarar, en la rebelión de Tupac Amara: "que no dudaría tomar el fusil en mano para guiar mi clero hasta el real enemigo". En el caso de $i$ Quito, muy pronto emergió en la conciencia de los indios la convicción de que la Iglesia era parte del sistema de dominación a través del comportamiento de sus clérigos. De aquí, por ejemplo, la acusación lanzada contra el cura Mariano Meló, en la puerta de la Iglesia de San Pablo de la Laguna, de ser "alcahuete" (de la Aduana) y pese a encontrarse con la Eucaristía en las manos (pg. 200). En Cayambe, igualmente, ante el rechazo del cura de entregar a los rebeldes al gobernador Puento y a la mayordoma de Temporalidades Ascensia Suárez, las indias Micaela Quascota y Manuela Lanchango "le metieron las manos en la cara al Cura estando con el Santísimo Sacramento en sus manos... lo trataron de Indio alcahuete de la Aduana. Que vendía a las criaturas mandándolas herrar por orden de su Señoría para que pagasen la Aduana" (pg. 210).

En la supresión de las rebeliones quiteñas, asimismo, los clérigos jugaron un papel de primer orden, bien sea a través de 
prédicas conminatorias $\mathrm{o}$ de procesiones en medio del tumulto de los rebeldes. En uno como en otro caso, sin embargo, sus esfuerzos fueron prácticamente vanos. En Columbe, esta vez, al tratar el religioso de contener la rebelión mostrando al Santísimo Sacramento e hincándose de rodillas, los sublevados le pidieron: "que salga fuera del Pueblo, porque también le matarían; que no era Dios el que tenía en las manos, sino una tortilla hecha por el Sacristán" (pg. 300). Es cierto que las rebeliones constituyen momentos privilegiados en la historia de las sociedades y que sus estallidos desnudan sus mismos basamentos y las convicciones más profundas de sus hombres. Como los oprimidos se expresan sólo en la acción, es la lectura de sus actos que permite descifrar el sentido de su historia. La actitud descrita de los indios frente a la institución eclesiástica pareciera revelar los límites de la así llamada "conquista espiritual" de América. En este sentido, el sincretismo religioso de la población andina, por lo menos en el período colonial, no habríase dado a nivel de su contenido sino que significaría una amalgama muy precaria entre el culto andino, a nivel de su contenido, y las expresiones del culto católico, a nivel precisamente de su forma. Las rebeliones eran justamente una ocasión propicia para el desenlace de esta ambigüedad. Una discusión más profunda de estos problemas exigiría aquí también una cuidadosa investigación sobre la Iglesia en la Audiencia de Quito, pero que al mismo tiempo evitara repetir los monocordes enunciados de una añeja historia institucional para más bien privilegiar el análisis del contenido y la transmisión del Mensaje y de las reacciones a su impregnamiento en la conciencia de la población sometida.

Resta, finalmente, un último problema por discutir. Se refiere a la relación de estos movimientos con la posterior emancipación política de Quito respecto a España, es decir la problemática privilegiada de toda la tradicional historiografía nacional que está siempre a la búsqueda de todo "síntoma", de "progromos" internos que anuncien la Independencia. Ahora bien, pese a que los indios quiteños se alzaron en contra de la "numeración" y de las "aduanas", es decir dos de las manifestaciones más visibles de la explotación colonial, en ninguno de los diez casos propuestos por Moreno (nótese que el último es de 1803) se encuentra la más mínima evidencia de que estas rebeliones intentaran la ruptura política con España. En el más extremo de los casos, Columbe en 1803, los indios quisieron cancelar todo el sistema de tributación y proceder a un reparto de las tierras detentadas por los terratenientes blancos, mientras que su líder - Antonio Tandaso Montoya y Machala- presentándose como el "Cacique libertador" buscaba la reconstitución de un señorío étnico. Pero la misma segmentación de este movimiento impidió la realización de sus proyectos. Así como el Perú tuvo que esperar a San Martín y Bolívar, la independencia de Quito fue impuesta por las bayonetas de Antonio José de Sucre $^{3}$. ¿Por qué, entonces, las rebeliones indias del Ecuador, como las del Perú y Bolivia, no pusieron en discusión el estatuto colonial?

La razón más obvia es que en esta pelea de minorías que en el fondo es la Emancipación, no hubo ningún planteamiento significativo que verdaderamente pudiera despertar la adhesión de la población indígena. Esto no significa, para ser más preciso, que los indios dejaran de "participar" en estas guerras. Ellos estuvieron en el campo de batalla, con el mismo heroísmo que habían mostrado a lo largo de todo el siglo XVIII, pero ahora matándose entre ellos mismos, por una causa que no era necesariamente la suya. A la segmentación que caracterizó su propio movimiento, y es esta la segunda de las razones, debe añadirse ahora la segmentación-oposición que existía entre los diversos estamentos étnicos que componían la sociedad colonial. Por grande que fuese la ambición de los criollos blancos de las regiones andinas para tomar en sus manos la conducción política de esta parte del Continente, 
mucho más era su temor de verse aplastados por una movilización independiente de los indios que los Criollos mismos, en algunos casos, contribuyeron imprudentemente a despertar. $\mathrm{Y}$ es este movimiento contradictorio de clases y etnias al interior del proceso de la Emancipación que nos coloca al borde mismo de un análisis del juego múltiple entre conciencia tribal, conciencia étnica, conciencia de clase y conciencia nacional. Este análisis recién empieza a ser planteado en la moderna historiografía de la América Latina y serán sus conclusiones las que contribuirán al rescate de la experiencia revolucionaria de este Continente. Es el camino a ese horizonte que está grandemente facilitado por sólidas monografías como la escrita esta vez por Segundo Moreno.
1/ Cf. Oscar Cornblit, "Society and Mass Rebellion in Eighteen-Century Perú and Boiivia", in St. Aníhony's Fapers, n? 22, Oxford, 1970.

2/ Boleslao Lewin, La rebelión de Tugac Amara,
Buenos Aires, 1957, pág. 433.

3/ John Lynch, The Spanish American Revolutions, 1808-1826, New York, 1973, pp. 235 - 248. 